\title{
Studies on Mechanical and Electrical Properties of Inter Penetrating Networks (IPN's) Of UF-PVC
}

\author{
Dr. S. SOUNDARARAJAN \\ Dept of Plastics Technology, Central Institute Of Plastics Engineering And Technology, \\ Guindy, Chennai- 600 032. India.
}

\begin{abstract}
UF (urea - formaldehyde) and PVC (polyvinyl chloride) raw materials which are in the powdered form are mixed in a high speed mixer in the compositions 85:15, 75:25 \& 65:35 wt\%. Ca/Zn stearate (2\%) was added as a stabilizer for PVC, which is a heat sensitive material. Torque Rheometer studies were used to know the curing time of UF alone. For UF-PVC Inter Penetrating Networks (IPN's), Cup flow / Disc flow tests are used to know the stability time, and degradation time in compression molding machine.

Tensile strength, Cross braking strength, Impact strength, Rock-well hardness, Dielectric strength, Arc resistance \& Mold shrinkage as per Indian Standard / ASTM standards were determined. Impact strength was found to be improved for IPN's of UF. The shrinkage was slightly increased and the Hardness was maintained. Cross Breaking strength and dielectric strength were found to be good and slightly decreased.
\end{abstract}

\section{Introduction}

The cost of Blending of Plastics materials in a twin screw extruder [1] to make PAB's (Polymer Alloys/ Blends) is higher due to high cost of the Twin screw extruder. Also, the melt blending of the granules involves the use of high temperature heating in the barrel of the compounding extruder than the Temps involved in a two-roll milling machine or Ban-bury internal mixer. Because, the simple mixing of two different polymers from granules will not give better compatibility unless these above techniques are used for melt mixing of the Thermoplastics.

The IPN's (Inter Penetrating Networks) [2] are considered to be cheaper than PAB's. Since the IPN's are not involving the melt blending operation; if the raw materials are in powder from as in this studies. But only involves just mixing in a high speed mixer followed by compression molding or thermo set injection molding (injection-compression .molding for continuous / faster conversion like in an injection molding machine) The thermo-sets are easy to process with lower viscosity [3] and with lower clamping pressure but brittle and quickly degrades during compression molding just after curing is completed. Because thermo-sets are molded at the fusion / curing temperature in the mold unlike the Thermo plastics where the molded is having lower temperatures in the mold than the barrel Temp. Also the Thermo-plastics increase the thermal stability because of higher Oxidation Induction Time (OIT) and reduce the brittleness. If the thermo plastics are flexible, or semi rigid like poly olefins, Plasticized PVC the impact strength will be better, Hence, IPN's provides better properties with longer cure characteristics and with lower material cost.

In this IPN's study UF ( Urea Formaldehyde) one of the amino plastics which is cheaper [4] and widely Useful in electrical applications such as switches, plugs because of good electrical properties like CTI was taken as the cross linking thermo-set matrix., but poor resistance to heat and has higher water absorption. The PVC (Poly Vinyl Chloride) is taken as the other Thermo plastics component since PVC is not sensitive to moisture and also with good insulation characteristics and low cost. Both UF and PVC are self-extinguishing and hence similar flame resistance will be present in the IPN's. Also better Process-ability i.e. more residence time in the Barrel of thermo-set Injection machine can be achieved for thermo-sets (U.F.) in presence of thermo plastics (PVC) (with stabilizer for the PVC ). Since, the PVC has higher time for degradation about 20 minutes than that of UF which is having the curing time / degradation time about 4-5 minutes only. Hence, PVC was taken to modify the curing time and stability time of UF and to Study their Mechanical and Electrical properties.

\section{Experimental}

Material

Urea - Formaldehyde (UF) was obtained from Reich-hold company of India ltd., Madhavaram, Chennai-84. Polyvinyl Chloride (PVC) Extrusion Grade 67 R092 was obtained from AIPMA (All India PVC Resin Manufacturers Association ) India. PVC stabilizer Ca/Zn Stearate was Supplied by the CDH Chemical Suppliers, Chennai, India 
High Speed Mixing

III. Methods

The Urea - Formaldehyde (UF) and Polyvinyl Chloride are in the form of Powders. The UF-PVC IPN's are studied in three formulations 85:15, 75:25 and 65:35 Weight ratios; the plastics raw materials are weighed and added to an high speed mixer (Make Henschel, FRG) and mixed thoroughly at a RPM of 250 at Room temperature.

\section{By Torque Rheometer}

\section{Curing Time For UF}

The curing time for Urea-Formaldehyde (UF) was obtained by studying the Torque values with respect to time at a constant Temperature $\left(145^{\circ} \mathrm{C}\right)$, by using a Torque Rheometer (Haake, FRG) as per ASTM D 3795 Standards [5]. The point of the fusion, the curing time and the degradation time are obtained. The Curing time is 3.75 min for UF. The Torque studies for the UF : PVC + stabilizer (2\%) were also tried, but could not get the proper curing time except the valley point and fusion point due to machine problems.

\section{Curing Of IPN's By Cup Flow And Disc Flow}

A Cup flow mold test provides information regarding the flow characteristics and moldability as per ASTM D731. As the percentage of PVC was increased the cup flow timing at $145^{\circ} \mathrm{C}$ was also increasing. (The time after applying the clamping pressure (2500 psi), but before just starting of the rising of the clamping pressure is known as cup flow time). After this flow time, the materials were allowed in the mould itself, to continue under the same temperature further for curing until degradation starts. The mold was opened often and checked whether slight colour changes to pale yellow or bubbling / blistering were taking place or not, due to onset of degradation. By this way the approximate curing time was decided which was below the degradation time of IPN's (TABLE 1) Also, similar curing time was obtained with a sheet mold in the same compression press, at the same conditions using 5-10 gms for each formulations for a single trial to form a Disc like cured sheets. This test is known as Disc Flow Technique. The cure characteristics are ascertained by the compression molders by visual check up [6] of a molded part which is based upon the following criteria:-

a. Lack of sufficient rigidity when part ejected from the mold.

b. Surface appearance whether colour changes due to onset of degradation

c. Cracks, porosity

d. Blisters / Swelling

e. Warpage / shrinkage

f. Dullness

Hence for the Test specimen preparation these above points were considered.

\section{By Compression Molding Technique.}

The test specimens were made for UF and UF-PVC IPN's by using compression molding machine (Hindustan \& Hydraulics) at temp $145+5^{\circ} \mathrm{C}$ with clamping pressure 2500 psi. IS 2221 standard was followed for the test specimen preparation for various tests mentioned below.

TABLE 1- CURING TIME FOR UF-PVC IPN'S

\begin{tabular}{|c|l|l|}
\hline SI.No. & \multicolumn{1}{|c|}{ Materials } & \multicolumn{1}{c|}{ Curing time } \\
\hline 1. & $100 \%$ UF & 3 min 45 secs. By torque Rhometer \\
\hline 2. & $100 \%$ UF & $\begin{array}{l}4.00 \text { min By compression moulding } \\
\text { (Cup / Disc flow methods) }\end{array}$ \\
\hline 3. & $\frac{\text { Formulation l }}{85 \% \text { UF + 15\% PVC }}$ & $\begin{array}{l}6 \text { min 15 secs. By compression moulding } \\
\text { (Cup / Disc flow methods) }\end{array}$ \\
\hline 4. & $\frac{\text { Formulation ll }}{75 \% \text { UF + 25\% PVC }}$ & $\begin{array}{l}6 \text { min 45 secs. By compression moulding } \\
\text { (Cup / Disc flow methods) }\end{array}$ \\
\hline 5. & $\frac{\text { Formulation lll }}{65 \% \text { UF }+35 \% \text { PVC }}$ & $\begin{array}{l}7 \text { min 15 secs. By compression moulding } \\
\text { (Cup / Disc flow methods) }\end{array}$ \\
\hline
\end{tabular}

NOTE: $2 \%$ DOP Plasticizer - Wetting agent for UF \& PVC interface $2 \% \mathrm{Zn} / \mathrm{Ca}$ Stearate - stabilizer for PVC.

\section{Testing}

The tests were carried out as per ASTM or IS standards. For tensile strength, cross breaking strength, impact strength and dielectric strength tests the Indian standard IS 2221 for amino-plastics was followed. For other tests ASTM standards were followed.

Rockwell Hardness - ASTM D 785, 
Studies On Mechanical And Electrical Properties Of Inter Penetrating Networks (Ipn's) Of Uf-Pvc

Arc Resistance - ASTM D495,

Bulk Density - ASTM D 1105 and

Shrinkage - ASTM 955.

\section{Results And Discussion}

The curing time was observed by visual observations by Trial and Error Method during compression molding. The UF-PVC was cured by using a cup flow mold / sheet mold (for disc flow technique) on a compression press. It was found that the curing time was lower for the curing of urea formaldehyde resin. As the \% of PVC was increased the curing time was increased since PVC lowers the degree of curing partly by blocking the cross linking functional groups. Because PVC Polymer chains has higher Molecular Weight (If K - value 62.8, then Mol. wt. will be about 48,000) [7] than UF which are oligomers with mol. Wt. about 36004500 only. Hence IPN's are forming and will improve the process ability of the UF in presence of PVC.

Test specimens were prepared using compression molding and Tested for the following Tests.

\section{Tensile Strength}

The tensile strength values for UF and UF-PVC formulations are given in Table 2. The test results were found to be decreasing as the PVC percentage was increasing since the PVC is having lower Tensile strength than that of UF. Hence the above trend was observed in these UF-PVC inter penetrating Networks.

TABLE 2 - Mechanical, Electrical and Physical properties of UF-PVC IPN's

\begin{tabular}{|c|l|c|c|c|c|c|c|}
\hline $\begin{array}{c}\text { SL. } \\
\text { No }\end{array}$ & \multicolumn{1}{|c|}{ Property } & Units & UF & $\mathbf{8 5 : 1 5}$ & $\mathbf{7 5 : 2 5}$ & $\mathbf{6 5 : 3 5}$ & $\begin{array}{c}\text { PVC } \\
\text { Powder }\end{array}$ \\
\hline 1. & $\begin{array}{l}\text { Tensile strength } \\
\text { at break }\end{array}$ & $\mathrm{Kg} / \mathrm{Cm}^{2}$ & 487.5 & 477.8 & 470.9 & 465.4 & 430.450 \\
\hline 2. & $\begin{array}{l}\text { Cross Breaking } \\
\text { Strength }\end{array}$ & $\mathrm{Kg} / \mathrm{Cm}^{2}$ & 393.75 & 341.1 & 325.8 & 302.4 & 250.275 \\
\hline 3. & Impact Strength & $\mathrm{Kg}-\mathrm{cm} / \mathrm{cm}$ & 2.72 & 3.08 & 3.65 & 4.42 & $2.25-4.35$ \\
\hline 4. & $\begin{array}{l}\text { Rock well } \\
\text { Hardness }\end{array}$ & $\mathrm{R}-\mathrm{Scale}$ & 120 & 119 & 117 & 117 & 110 \\
\hline 5. & $\begin{array}{l}\text { Dielectric } \\
\text { Strength }\end{array}$ & Volt/mil & 421.92 & 393.98 & 383.56 & 375.82 & 375 \\
\hline 6. & Arc Resistance & Sec. & 142 & 102 & 110 & 105 & $60-80$ \\
\hline 7. & Bulk Density & $\mathrm{Gm} / \mathrm{cc}$ & 0.77 & 0.79 & 0.84 & 0.87 & 0.975 \\
\hline 8. & Mold shrinkage & $\%$ & 4.14 & 4.26 & 4.32 & 4.89 & 2.162 \\
\hline
\end{tabular}

\section{Cross Breaking Strength}

The cross breaking strength was also found to be decreasing steadily. The values are given in the Table 2 and Fig 1 . The cross breaking strength may be improved by adding small quantity of Mineral fillers such as $\mathrm{CaCO}_{3}$, so that the rigidity and hence flexural strength will increase in the IPN's which will also lead to increase in the Flexural modulus, during this cross breaking test at slow rate of deformation.

\section{Impact Strength, lzod (molded with Notch)}

Izod impact strength values were found to be increasing for all formulation than that of UF (Table 2 and Fig 2) since PVC has higher impact strength. If plasticizers like DOP's (Di-octyI phthalates) are used more at about 8-10 phr., the impact strength may be increasing further, like in plasticized PVC's. Also rubbers or flexible plastics like LDPE will increase the toughness and hence the impact strength may also be improved like in thermoplastic-elastomer blends. For application like electrical switches, this izod impact strength may not be important criteria, except during handling / transportation. But for applications such as dinner wares (cups \& plates) the Dart impact strength is more important and LDPE and flexible PVC may be used.

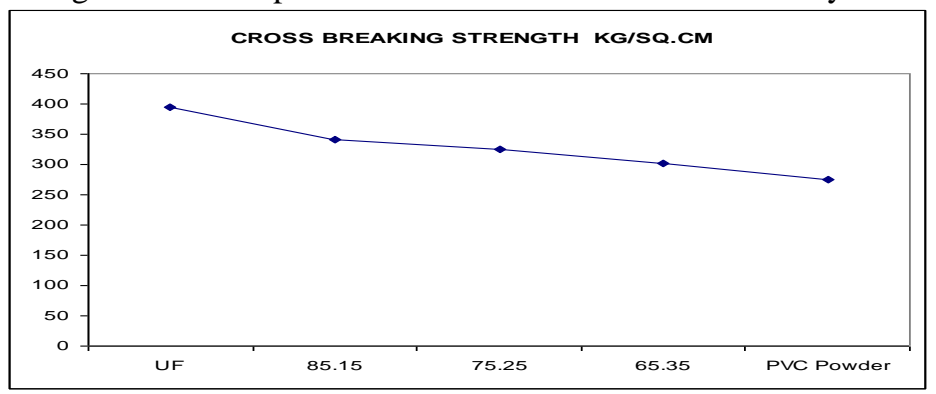

Fig. 1- Cross Breaking Strength of UF, UF-PVC IPN's of 85:15, 75:25, 65:35 and PVC 


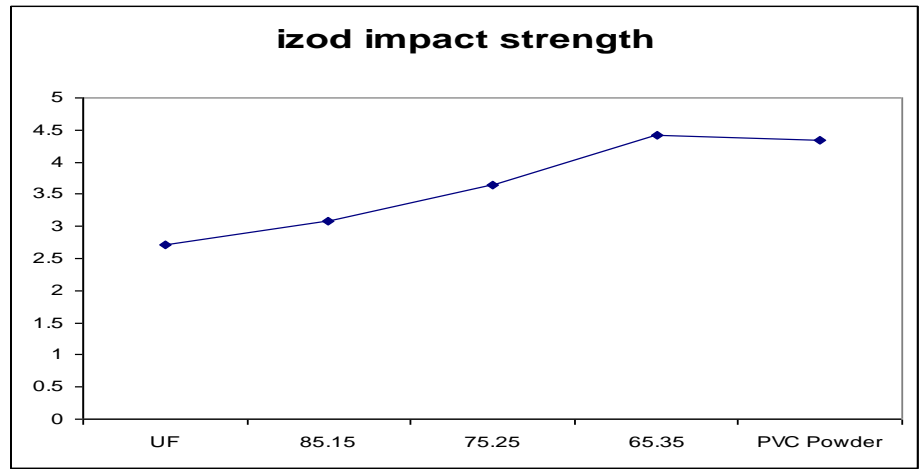

Fig. 2. Impact Strength of UF, UF: PVC IPN's of 85:15, 75:25, 65:35 and PVC

\section{Hardness}

The hardness values were tested as per the R-scale of Rockwell hardness and the values are found to be slightly lower by one unit for formulation I, and 3 units for formulations II \& III. The values are furnished in the Table 2.

\section{Arc Resistance}

The arc resistance values are found to be decreasing This value may be increased by using with mineral fillers (such as barites, zirconytes or alumina).

\section{Dielectric Strength}

The dielectric strength values are found to be decreasing as the PVC \% was increasing. The values are slightly higher than that of PVC. The values are provided in the table 2

\section{Mold Shrinkage}

The values are expressed in percentage and shown in Table 2 . The values are increasing as the percentage of PVC is increasing. PVC being a linear thermoplastic material prevents the degree of curing slightly. But even after molding, the UF reactive groups may be cross linking slowly at the room temperature and hence lowers the dimensions leading to higher shrinkage values, but will not make the products warping. If annealed properly, for large size products further the shrinkage can be reduced to a minimum.

\section{Conclusion}

The UF-PVC was found to be having better process-ability and thermal stability than that of UF since the molding time / curing time is higher. Also the properties such as impact strength was found to be better than UF itself. Further, the cost of the PVC is cheaper than that of UF and hence the UF-PVC IPN's will also be cheaper depending up the \% of PVC in the IPN's and also since only high speed mixing is used. No melt blending compounding techniques like two roll milling, twin screw extruder are required for IPN's unlike PAB's. Even if PVC is not fusing at the processing temperature the PVC may act as Polymeric filler like other additives such as fillers, flame retardants. However, at $150^{\circ} \mathrm{C}$ the $\mathrm{PVC}$ will be softening and hence miscibility and compatibility may be achieving in this IPN. Hence, properties of PVC may be imparted to the Inter Penetrating Networks.

\section{References}

[1]. Marks, "Encyclopedia of Polymer Science \& Engineering " A John Wiley Inter Science Publisher. New York Vol. 8,1987, p288

[2]. Stuart M Lee. "International Encyclopedia of Composites" VCH Publishers, Vol.2, 1990, p 378

[3]. J.A. Brydson, "Plastics Materials", Butter Worth Scientific London, Ed.6, 1995 p.650

[4]. W.V.Titow, "PVC Technology", Elesvier Applied Sci. Publishers, London, Utarki,"Polymer Blends and Alloys". Hanser publishers Ny.1982 p.15

[5]. Annual ASTM Standards Series Vol. 08-03 Philadelpia NJ. USA

[6]. Rolph E Wright, "Molded Thermosets", Hanser Publishers, Munnich, 1991, p 63 \& 72

[7]. W.V.Titow, "PVC Technology", Elesvier Applied Sci. Publisher, London, Ed. 4, 1984, p. 15. 